Motrivivência $\quad$ v. 26, n. 43, p. 287-299, dezembro/2014

http://dx.doi.org/10.5007/2175-8042.2014v26n43p287

\title{
FILOSOFIA DA TECNOLOGIA E EDUCAÇÃO FíSICA: tensões a partir do corpo
}

\author{
Fabio Zoboli? \\ Elder Silva Correia ${ }^{2}$ \\ Felipe Quintão de Almeida ${ }^{3}$
}

\section{RESUMO}

Artigo com o objetivo de apresentar e situar a Filosofia da Tecnologia como disciplina que aborda questões importantes aos estudos das intervenções do corpo em face à tecnologia ligada a estudos vinculados à Educação Física. A partir de uma busca em 05 periódicos do campo, visualizou-se 03 temas para análise: virtualização do corpo/movimento; doping; corpo acoplado à tecnologia. Como resultado, encontra textos que apresentam questões ligadas à Filosofia da Tecnologia - problematizações de cunho epistemológico, ontológico e axiológico. Conclui com reflexões sobre o levantamento realizado, lançando algumas questões para perspectivar estudos a partir da configuração encontrada.

Palavras-chave: Corpo; Tecnologia; Filosofia da tecnologia; Educação Física

1 Doutor em Educação. Docente do Departamento de Educação Física da UFS, São Cristóvão/Sergipe, Brasil. E-mail: zobolito@gmail.com

2 Graduado em Educação Física. UFS, São Cristóvão/Sergipe, Brasil.

E-mail: elder.correia17@gmail.com

3 Doutor em Educação. Docente do Departamento de Ginástica da UFES, Vitória/Espírito Santo, Brasil.

E-mail: fqalmeida@hotmail.com 


\section{INTRODUÇÃO}

Este artigo tem como objetivo apresentar e situar a Filosofia da Tecnologia como disciplina que aborda questões que consideramos caras aos estudos das intervenções do corpo em face à tecnologia. A Filosofia da Tecnologia "[...] trata de uma realidade que pode (e deve) ser tematizada, [...] pois encerra questões tanto ontológicas quanto epistemológicas, tanto éticas quanto estéticas, tanto relativas à filosofia política quanto referentes à filosofia da história" (CUPANI, 2011, p. 9). Sendo assim, este texto se propõe a tencionar estas questões da Filosofia da Tecnologia no contexto de algumas problemáticas ligadas a pesquisas vinculadas ao campo da Educação Física, em que o corpo (hibridizado à tecnologia) é o foco de análise. Para isso, procuramos identificar como essa discussão se materializa em periódicos da Educação Física. Fizemos, assim, uma busca em 05 periódicos da Educação Física: Revista Brasileira de Ciências do Esporte (RBCE); Movimento; Motrivivência; Motriz e Pensar a Prática. Os critérios de escolha foram a boa avaliação no Qualis-periódicos da CAPES, bem como a sua importância no âmbito da Educação Física. A triagem dos artigos foi feita pela opção de busca no site de cada periódico; desse modo, digitamos as palavras corpo e tecnologia(s); técnica(s); corpo híbrido; Filosofia da tecnologia, cibercultura e procuramos nas opções "título" e "resumo". Cabe destacar que os artigos que nos interessavam eram apenas os que tratavam da relação corpo-tecnologia, assim como os que eram das Ciências Sociais e Humanas. Não vamos considerar, assim, os estudos com foco na perspectiva biodinâmica, assim definida por Carvalho e Manoel (2011, p. 392):

\begin{abstract}
A biodinâmica compreende as atividades de pesquisa dentro de subdisciplinas como bioquímica do exercício, biomecânica, fisiologia do exercício, controle motor, aprendizagem e desenvolvimento motor, além de alguns campos aplicados, como nutrição esportiva e treinamento físico e desportivo. As linhas de pesquisa na biodinâmica são orientadas pelas ciências naturais.
\end{abstract}

Neste sentido, foram encontrados inicialmente 27 artigos. A busca resultou em 03 temas/categorias (que, em parte, se sobrepõem): a primeira está relacionada com a virtualização do corpo e do movimento; a segunda se refere à problemática do doping; a terceira é a do corpo acoplado à tecnologia. Estaremos atentos nestes textos somente àqueles que tragam, no bojo de suas discussões, as questões ligadas à Filosofia da Tecnologia: questões de cunho epistemológico, ontológico e axiológico, pois estas são as problematizações que aproximam os estudos do corpo ao contexto da Filosofia da Tecnologia. Desta forma, foram utilizados para a análise 17 textos.

Pela manipulação por meio da tecnologia, o corpo cada vez mais vem sendo alvo do domínio da mesma. O corpo vem se transformando sob as condições que as ciências/tecnologias lhe oportunizam, a fim de potencializar sua natureza. Dessa forma, a tecnologia constantemente está buscando dominar e ultrapassar as fronteiras naturais do corpo, colocando-o, muitas vezes, sob suspeita no ponto de vista ontológico, epistemológico e ético.

O campo da Filosofia da Tecnologia é novo como uma disciplina acadêmica; no entanto, é antigo no que tange às ponderações relacionadas às contendas filosóficas das relações do humano com a natureza. A tecnologia nos afeta e nos desafia diariamente, 
pois nosso corpo, como vetor semântico de relação com o mundo, fica exposto constantemente a operadores epistêmicos ligados a ela.

Este artigo está organizado em duas seções: num primeiro momento, apresentamos a Filosofia da Tecnologia com o intuito de situar o leitor nas reflexões abarcadas por ela. Na sequência, tratamos, de forma panorâmica, de algumas questões concernentes ao processo contemporâneo de manipulação do corpo pela tecnologia; o propósito é estabelecer tensões com objetos de pesquisa e estudos publicados no campo da Educação Física. Neste sentido, buscamos identificar se em tais estudos são abordadas questões (ligadas à tecnologia) que também interessam à Filosofia da Tecnologia, como questões de cunho ontológico, epistemológico e axiológico.

\section{Filosofia da tecnologia: breve apresentação e questões}

Para Cupani (2011), a Filosofia da Tecnologia, embora antiga como assunto de reflexão de alguns pensadores isolados, é recente como disciplina acadêmica. No que tange à história da Filosofia da Tecnologia, não há um consenso na bibliografia pesquisada. O livro de Mitcham (1989), “Qué es la filosofía de la tecnología?",é um dos clássicos dessa área. Nele, o autor defende que o alemão Ernst Kapp (1808-1896) foi o fundador da Filosofia da Técnica com sua obra "Grundlinien Einer Philosophie der Technik" ("Fundamentos de uma Filosofia da Técnica"), publicada em 1877. De modo mais recente, conforme Cupani (2011), os esforços decisivos na direção da formação de uma comunidade de estudiosos dedicados a essa nova área filosófica são atribuídos ao filósofo Paul T. Durbin, que organizou importantes reuniões internacionais de Filosofia da Tecnologia na década de 1970.

Na opinião de Mitcham (1989), existem duas perspectivas quando se discorre a respeito da Filosofia da Tecnologia: uma representada pelos estudiosos que partem da "Engenharia"; e outra que está situada no âmbito da "Filosofia":

\begin{abstract}
A 'Filosofia da Tecnologia' pode significar duas coisas completamente diferentes. Assim, quando 'da tecnologia' indica qual é o sujeito ou agente, a Filosofia da Técnica é o intento dos tecnólogos ou engenheiros, de elaborar uma filosofia estritamente voltada à técnica ou à tecnologia. Quando 'da tecnologia' indica o objeto que será tratado, então a Filosofia da Técnica alude ao esforço, por parte do filosofar, de assumir seriamente, a técnica como um assunto de reflexão sistemática. A primeira tende a ser mais benévola com a tecnologia, a segunda mais crítica (MITCHAM, 1989, p. 20).
\end{abstract}

Quando nos propomos uma postura de filosofar sobre algo, é preciso inicialmente formular alguns questionamentos a respeito do objeto. Neste sentido, perguntamos: o que é tecnologia? Ou, o que se entende sobre tecnologia? Essas perguntas apresentam inúmeras bifurcações e perspectivas. Vejamos, a partir Cupani (2001), algumas problemáticas que envolvem a resposta a tal pergunta: "Aquilo que denominamos tecnologia, se apresenta, pois, como uma realidade polifacetada: não apenas em forma de objetos e conjuntos de objetos, mas também como sistemas, como processos, como modos de proceder, como certa mentalidade" (CUPANI, 2001 p. 12).

Em termos de filosofia clássica, trata-se da questão do ser ou da essência da 
tecnologia. "É ela uma 'coisa', um processo ou o quê? Trata-se de algo real ou apenas de uma noção com que pensamos um conjunto de objetos, atividades e eventos? Há uma diferença essencial entre técnica e tecnologia?" (CUPANI, 2001 p. 23).

Sobre a diferença entre técnica e tecnologia, Craia (2003, p. 35) compreende que "[...] dentro do horizonte preponderante no nosso tempo, o mais habitual é que a expressão 'técnica' faça referência a um certo âmbito simplesmente procedimental e rudimentar; enquanto "tecnologia", pelo seu componente de 'logos', corresponda à instância de uma praxis mais elaborada e de um conhecimento mais especificado". José Sannmartín, apud Craia (2003, p. 35), entende que: "[...] classicamente a técnica é o gênero; a tecnologia é uma espécie dentro desse gênero, exatamente, a técnica que resulta de aplicar a ciência". Para Cupani (2011, p. 13), “[...] de modo evidente, tudo ou quase tudo a que nos referimos ao falarmos da tecnologia tem alguma veiculação com o que denominamos técnica".

Neste sentido, a técnica seria um modo de operar sobre algo. Isso não quer dizer que é um conhecimento puramente "prático", mas, sim, que está em uma constante e intensa relação com um conhecimento - ou teoria - num modo de retroalimentação, como se fossem engrenagens que funcionam juntas e interdependentes. Sob este caráter de operação a respeito de algo, compreendemos que a técnica faz parte de um domínio da natureza (externa e interna), na medida em que é por meio dela que o ser humano busca sanar as necessidades surgidas no entorno de sua existência. Para Ortega y Gaset (1965, p. 21),

\begin{abstract}
De onde resulta que esses atos modificam ou reformam a natureza ou circunstância, conseguindo que nela haja o que não há - seja que não há aqui e agora quando é necessário, seja que não há em absoluto. Pois bem: esses são os atos técnicos, específicos do homem. O conjunto deles é a técnica, que podemos definir como a reforma que o homem impõe à natureza em vista da satisfação de suas necessidades.
\end{abstract}

Heidegger, por sua vez, adverte que devemos considerar a diferença entre a origem grega do termo e sua concepção moderna. Para ele (1999, p. 21-22), o termo technè não significa o mesmo que técnica nos sentidos modernos de métodos e atos de produção, mas um

[...] conhecer-se no acto de produzir. Conhecer-se é um gênero de conhecimento, de reconhecimento e de saber. $\mathrm{O}$ fundamento do conhecer repousa, na experiência-grega, sobre o fato de abrir, de tornar manifesto o que é dado como presente. No entanto, o produzir pensado à maneira grega não significa tanto fabricar, manipular e operar, mas mais o que o termo alemão herstellen quer dizer literalmente: stellen, pôr, fazer levantar, her, fazendo vir para aqui, para o manifesto, aquilo que anteriormente não era dado como presente.

O que diferencia a technè da "técnica moderna" é o fato de que esta última, em seu ininterrupto processo de disponibilização de tudo o que há, oculta e fecha o acesso ao desencobrimento enquanto tal, enquanto que a téchne visa, permanentemente, o desencobrimento. Para o filósofo alemão, a técnica tradicional tem a ver com o conhecimento, com o produzir humano no sentido de produzir "desde outro", e, assim, seria um desocultar, um "desabrigar produtor". Já técnica moderna, na mesma 
medida em que é um desabrigar, é também um desafiar a natureza para que esta se mostre como algo disponível para o ser humano, ou seja, é um impor-se a natureza para que ela se apresente apenas como esse algo disponível (CUPANI, 2011). Mais ainda,

[...] esclarece Heidegger: trata-se de um colocar a natureza na situação de se obter o máximo de proveito com o mínimo de despesa, que opera explorando, transformando, armazenando e distribuindo os recursos naturais, de maneira dirigida e asseguradora. Heidegger compara o antigo moinho de vento, que não retirava a energia do ar para armazená-la, mas se harmonizava com a força eólica, com a moderna exploração do meio ambiente (CUPANI, 2011, p. 42).

O ser humano, no decorrer de sua existência, busca sanar suas necessidades pulsionais para planos de outras ordens - inclusive sendo desafiado pela técnica. Ao fazer isso, o homem se diferencia dos demais animais no sentido da utilização da técnica. Para Cupani (2011, p. 32):

O homem não é tampouco a sua circunstância [ou natureza]: 'está tão só mergulhado nela e pode, em alguns momentos, sair dela e pôr-se dentro de si, recolher-se, ensimesmar-se' para projetar atos que não Ihe são ditados nem pelo instinto nem pela circunstância. O comum a esses atos é a invenção de um procedimento que nos permite obter o que não há na natureza, mas de que precisamos.

No entanto, tal manipulação/domínio sobre a natureza (corporal) traz um paradoxo no instante em que tal movimento gera um processo de regressão e a própria natureza domina o ser humano. Ao dominar natureza/corpo, o ser humano passa a ser senhorio da mesma, estabelecendo, assim, uma relação de objeto com o próprio corpo. Ou seja, o ser humano passa a ser ao mesmo tempo dominador e dominado. Neste sentido, Vaz (1999, p. 91) destaca que

Se somos senhores da natureza [...] e se reconhecemos na natureza um outro a ser dominado, colocamo-nos em um paradoxo, ao pensarmos que também somos parte da natureza, ou, dito de outra forma - talvez mais 'esclarecida' -, que temos parte da natureza em nós. Tornamo-nos outros em relação a nós mesmos, objetos perante um espelho.

A Filosofia da Tecnologia formula questões que dizem respeito à ontologia, epistemologia e a ética/bioética, formulando questionamentos como: o que é algo natural? O que é artificial? O que diferencia natural e artificial? O que significa alterar/ produzir/destruir algo natural? O artificial descaracteriza a natureza do humano? Natural e artificial não são tensões de um mesmo e único processo do devir ontológico? Pode algo artificial se tornar autônomo e mudar seu rumo? Na mesma medida, ela designa demandas de cunho epistemológico que dizem respeito a problemas produzidos pelos saberes implicados pela tecnologia: qual a relação entre ciência e tecnologia? Existe um saber que não seja científico no âmbito da tecnologia? Qual o lugar do saber prático na tecnologia? O que diferencia um saber tecnológico de um saber científico? O que significa saber usar uma tecnologia? Que novas linguagens a tecnologia produz? A tecnologia é parte do processo da "natureza" humana ou de sua cultura? De igual forma, a Filosofia da Tecnologia levanta questões de cunho axiológico, no sentido de se estabelecer valores de cunho político e ético: a tecnologia é neutra? Aos interesses 
de quem está determinada a tecnologia? Qual a índole de um produto tecnológico? $\mathrm{O}$ que difere a beleza natural da beleza artificial? O homem tem mais valor que a natureza? Até que ponto o homem pode usar a natureza para seu próprio benefício? Qual o preço da exploração da natureza para as futuras gerações? Como deve proceder uma experimentação com um animal? Com um ser humano? Com os fetos humanos? O que é uma substância proibida? O que é uma trapaça no uso da tecnologia para com o corpo? Quais os limites que devemos ter para com os estudos da genética? E para com os estudos de energia nuclear?

Na sequência, nos propomos a tencionar algumas questões da Filosofia da Tecnologia no contexto de algumas problemáticas ligadas a estudos vinculados ao campo da Educação Física, em que o processo contemporâneo de manipulação do corpo pela tecnologia foi centrado como foco de análise.

\section{Corpo e tecnologia: a Educação Física}

É importante, para uma melhor compreensão dos regimes de sentido associados ao corpo, uma análise da história e da filosofia da técnica, pois a evolução da técnica é solidária de uma transformação dos processos de instrumentalização do Corpo (BÁRTOLO, 2007, p. 242).

O corpo é central na Educação Física não só por suas práticas estarem historicamente vinculadas ao movimento do mesmo, mas também porque todas as vezes que se pensou a Educação Física como campo de conhecimento e/ou ciência, o corpo e suas manifestações de movimento apareceram como centrais para conjecturar as tramas epistemológicas. As manifestações culturais de práticas ligadas ao corpo são emblemáticas e centrais para a constituição das práticas da Educação Física como conteúdos. No cenário da Educação Física, o corpo tem se apresentado como objeto de estudo a partir de várias problemáticas. "A problemática do corpo pode apresentar indicadores para a configuração epistemológica da Educação Física, haja vista a existência de um número significativo de pesquisas que enfocam questões relativas ao corpo" (NÓBREGA, 2006, p. 60).

Neste início de segundo milênio, uma das características mais notáveis, no que tange a condição humana como corpo, é a sua fusão com a máquina. "Do lado do organismo: seres humanos que se tornam, em variados graus, 'artificiais'. Do lado da máquina: seres artificiais que não apenas simulam características dos humanos, mas que se apresentam melhorados relativamente a esses últimos" (TADEU, 2009, p. 11):

Implantes, transplantes, enxertos, próteses. Seres portadores de órgãos "artificiais". Seres geneticamente modificados. Anabolizantes, vacinas, psicofármacos. Estados "artificialmente" induzidos. Sentidos farmacologicamente intensificados: a percepção, a imaginação, a tesão. Superatletas. Supermodelos. Superguerreiros. Clones. Seres "artificiais" que superam, localizada e parcialmente (por enquanto), as limitadas qualidades e as evidentes fragilidades dos humanos. Máquinas de visão melhorada, de reações mais ágeis, de coordenação mais precisa. Máquinas de guerra melhoradas de um lado e outro da fronteira: soldados e astronautas quase "artificiais", seres "artificiais" quase humanos. Biotecnologias. Realidades virtuais. Clonagens que embaralham as distinções entre reprodução natural e reprodução artificial. Bits e bytes que circulam, indistintamente, entre corpos humanos e corpos elétricos, 
tornando-os igualmente indistintos: corpos humano-elétricos (TADEU, 2009, p. 12-13).

Como mencionado na introdução, encontramos 27 textos nos periódicos da Educação Física que nos remetem a estudos que tratam da hibridização do corpo com a tecnologia. Porém, somente 17 deles tratam de questões de cunho epistemológico, ontológico e axiológico - ou seja, textos que giram em questões que são de interesse da Filosofia da Tecnologia. Os 17 textos estão assim distribuídos nas revistas: RBCE (08), Motrivivência (04); Motriz (03); a Movimento (02) e Pensar a Prática (00).

No que diz respeito ao tema virtualização do corpo/movimento, foram encontrados 07 textos. O estudo de Gama (2005) discorre sobre a técnica, a tecnologia, bem como o uso dos jogos digitais; introduz o conceito de "ciberatletas" para realizar uma discussão epistemológica no que tange ao esporte e ao movimento humano. Neste sentido, ele abarca questões não só epistemológicas, mas também ontológicas (quando questiona o que pode ser a técnica/ tecnologia bem como quando propõe uma mudança de olhar sobre o atleta, concebido, a partir de então, como um "ciberatleta") e axiológicas (na medida em que questiona também o uso da tecnologia e os valores que envolvem esse uso). No plano da axiologia, podemos englobar também o estudo de Costa e Betti (2006), quando propõem, através dos "jogos virtuais" mais conhecidos pelos alunos, experiências corporais educativas no meio escolar.

Para introduzirem novos elementos para a discussão sobre o conceito de experiência, Silva, Lazzarotti Filho e Silva (2010) trazem reflexões a respeito das práticas corporais virtualizadas, o que podemos considerar também como interesses axiológicos, mas, também, ontológicos, quando se perguntam sobre a natureza da experiência em face à realidade virtual. Na esteira das questões axiológicas e ontológicas, podemos incluir também o estudo de Cruz Junior e Silva (2010), que faz uma leitura dos jogos eletrônicos no século XXI para tratarem da conexão entre corpo, subjetividade e tecnologia pelo princípio da cibercultura. Ainda no plano da cibercultura, Zoboli e Silva (2010) tecem algumas considerações ontológicas a respeito da relação entre Educação Física e cibercultura. O estudo de Araújo et al. (2011) remete também a problematizações axiológicas na medida em que buscou analisar o processo de virtualização esportiva e sua interferência na cultura corporal de movimento e na Educação Física; assim como também o trabalho de Finco e Fraga (2012), que busca entender a percepção de usuários em relação jogo (virtual) Wii Fitt.

O processo contemporâneo de virtualização do corpo amplia sua circulação e trocas. O transplante de órgãos, o esperma, o sangue, tudo é transportável para uma rede de corpos beneficiários/consumidores. O ultrassom, a tomografia e os raios-X nos permitem atravessar a pele sem cortes e ver além das camadas do corpo. O telefone separa a voz do corpo e a leva até o interlocutor da chamada; meu corpo e minha voz estão aqui; meu corpo sonoro está em outro lugar potencializado por um artefato tecnológico. Quando vejo uma partida de futebol televisionada meus olhos se unem a um "grande olho coletivo" e ao fazê-lo se torna um órgão virtualizado. Nos jogos eletrônicos, quem é o atleta? O operador (o ciberatleta) ou a máquina (o avatar)? Seria isso uma espécie de encarnação? 
Quando mergulhamos nas profundezas do mar acoplados com artefatos de mergulho ou quando saltamos de um avião munidos de paraquedas, nosso corpo se virtualiza/ potencializa e nos tornamos "quase peixes" e "quase pássaros".

O virtual tem a ver com o não estar presente, com novos espaços e novas velocidades, mas também com a passagem do interior ao exterior e do exterior ao interior. No virtual, lugar e tempo se misturam. Para Lévy (1996, p. 15):

A palavra virtual vem do latim medieval virtualis, derivado por sua vez de virtus, força, potência. Na filosofia escolástica, é o virtual que existe em potência e não $o$ ato. $O$ virtual tende a atualizar-se, sem ter passado, no entanto, à concretização efetiva ou formal. A árvore está virtualmente presente na semente.

Nos estudos reunidos na categoria doping, há aqueles que o apresentam sob o viés das relações de gênero, como, por exemplo, no instante em que descobriram a manipulação de hormônios e a necessidade de comprovar o gênero das mulheres atletas (LESSA; VOTRE, 2013), o que podemos considerar questões axiológicas. Encontramos, além disso, estudos que propõem discutir o doping no esporte feminino e as mudanças verificadas no corpo das atletas durante a história (DEVIDE; VOTRE, 2005), tema este que também envolve questões axiológicas. Há estudos que trazem o doping como um problema ético (COSTA et al, 2005); outros que tentaram analisar o doping a partir de episódios envolvendo atletas, assim como também o doping como um problema técnico para o esporte, relacionando isso com o uso de drogas para o aumento da performance em outras esferas sociais (VAZ, 2005).
Neste estudo de Vaz (2005), percebemos as tensões no que tange as questões de ordem ontológicas, epistemológicas e axiológicas. Visualizamos, também, trabalhos sobre o doping que trazem à tona a questão do puro e impuro (PERERA; GLEYSE, 2005), bem com dos argumentos que sustentam $O$ mesmo (TAVARES, 2002), ou seja, questões epistemológicas, ontológicas e axiológicas. O texto de Manske (2013) considera que o esporte está pautado numa epistemologia dualística e, assim, não está preparado para lidar com o uso da tecnologia e a potencialização do humano, o que envolve, sobretudo, questões ontológicas e epistemológicas. No entanto, para esse autor essa é uma questão bastante controversa se for considerado que o uso de alguma tecnologia - droga, manipulação genética, prótese/material - parece ser imprescindível para o esporte de alto rendimento e que nele há pouco do que se poderia chamar de "natural" no que se refere à relação com o corpo - como se pudéssemos delimitar o que seria uma natureza "livre" dos condicionantes culturais da tecnologia (VAZ, 2005).

No que se refere ao acoplamento de tecnologias no corpo - terceira categoria anunciada - podemos visualizar nos estudos em Educação Física 03 aparições. Assim apresentamos o texto de Santa'Anna (2000), que discute as relações entre cultura e tecnologia tendo como foco o esporte, o corpo dos atletas e as tecnologias acopladas a eles, oportunidade em que questões epistemológicas, axiológicas e ontológicas são abordadas. Para a autora, inclusive, é impossível pensar o esporte sem a hibridização entre os corpos dos atletas e os diversos tipos de tecnologias que os permeiam. Já Abrão e Silva (2004) utilizaram de um lócus diferente para pensar tal hibridização; 
os autores buscaram entender a relação entre arte, ciência e tecnologia a partir da dança híbrida, procurando entender o papel da tecnologia acoplada ao corpo (de dançarinos), nos espetáculos de um grupo de dança. O estudo de Machado, Zanetti e Moioli (2011) objetivou verificar, em um ambiente escolar, as transformações e influências da tecnologia em aulas de Educação Física, o que caracteriza questões axiológicas, na medida em que questiona seu uso/incorporação.

E termos fenomenológicos, o corpo acoplado à tecnologia provoca uma relação existencial de "incorporação" - embodiment. Por exemplo, quando fazemos uso de óculos para potencializar nossa condição natural de visão, esta tecnologia começa a fazer parte de nossa experiência, modificando nossa relação com o mundo. Os óculos se encarnam no sujeito e passam a ser uma extensão de seu corpo. Se o ser humano existe via corpo, ou seja, se a condição humana é corporal, subtrair ou atrelar alguma "coisa" a este corpo é de alguma forma fazer com que esta "coisa" se torne corpo - in corpore (LE BRETON, 2011). Neste sentido, Bartolo (2007, p. 232) enfatiza que: “A prótese opera então por corporização a partir de si. Ela é o ponto-central da corporização. Quando me é colocada uma mão protésica o meu corpo é corporizado a partir dela, ela constitui-se como Órgão-Corpo". Por outro lado, o uso de um instrumento/artefato tecnológico reduz a percepção a apenas o recebido por esse meio. Como menciona Cupani (2011, p. 125),

Quando vejo a lua sem tecnologias, a minha percepção é com todo meu corpo em ação; já através do telescópio, o setor da superfície lunar enxergado é apenas um fenômeno óptico. [...] Cabe, no entanto, observar que as nossas capacidades de percepção frente a realidade permanecem como referências primitivas e centrais em toda experiência tecnologicamente mediada.

No entanto, a relação fenomenológica do corpo com a tecnologia não se limita a apenas relações de incorporação. Esta experiência gera relações de cunho hermenêutico. Por exemplo, quando um árbitro de ginástica lê uma série de um ginasta descrita numa súmula, ele está se relacionando com um artefato técnico, que pela sua condição faz remeter a outra coisa. Ou seja, quando o árbitro vê a série descrita na súmula com os códigos de pontos anunciados, ele visualiza o atleta e a sua performance no que tange à execução de seus movimento. A leitura se torna uma técnica incorporada.

O corpo nas suas mais variadas fusões com a tecnologia - aqui representado pelas 03 categorias - nos remete a ideia de híbridos. Seres híbridos são seres de fronteira, como por exemplo: o lobisomem, Frankenstein, o Minotauro, o cyborg, ${ }^{4} \mathrm{e}$ um sem fim de figuras históricas - mitológicas ou científicas. Reduzindo a exemplificação ao nível do cyborg (homem/máquina), o que

4 O termo ciborgue deriva de cyborg, que é a abreviatura de cyberneticorganism. Kybernetes vem do grego, que significa "o homem que dirige". 
nos permite afirmar se "é um homem!" ou se "é uma máquina!" na confrontação do híbrido não é a identidade nem de homem e nem da máquina, mas, sim, a intensidade, ou seja, os agentes de intensificação sígnica - agenciamento de linguagem. "De facto se a identidade não se deixa nunca fixar ela deixa-se enunciar. O que distingue uma enunciação de cariz identitário de uma outra é o tipo de intensificação que se agencia pela linguagem" (BÁRTOLO, 2007, p. 178-179).

\section{CONSIDERAÇÕES FINAIS}

O presente artigo apresentou a Filosofia da Tecnologia como um possível referencial para discutir questões - sobretudo de cunho epistemológico, axiológico e ontológico - ligadas a hibridização do corpo com a tecnologia. A partir disso, observamos em artigos publicados em 05 periódicos da Educação Física brasileira como possíveis questões sobre esta temática estão sendo tratadas e discutidas nas pesquisas no âmbito do campo.

Frente às análises realizadas, apresentamos, à guisa de considerações finais, algumas questões com a intensão de perspectivar futuros estudos a partir da Filosofia da Tecnologia no campo da Educação Física: quais são os limites dos produtos tecnológicos para a prática esportiva? O que pode ser considerado doping? Até que ponto o uso de alguma tecnologia para o aumento da performance é ético ou não? O que caracteriza um doping tecnológico?

Ao vermos os Jogos Olímpicos, Paraolímpicos e os Gay Games, percebemos mais ainda a presença maciça da tecnologia no aumento da performance. Nesse sentido, perguntamos: por que se precisa dividir os atletas e, portanto, organizar jogos segregados (atletas "normais" de um canto; paratletas em outro; "atletas homossexuais/ queer" ainda em outro)? Será que haverá cada vez mais divisões no esporte? Será que chegaremos a um tempo em que as modalidades esportivas serão divididas por categorias com atletas que fazem uso do doping "atletas artificiais", e outros atletas puros "naturais"? Neste sentido, pensar uma epistemologia para conceber a condição híbrida não seria uma proposta de superação das fronteiras das tradições dualísticas na medida em que desestrutura as oposições dualísticas sugeridas?

\section{REFERÊNCIAS}

ABRÃO, E.; SILVA, A. M. Reflexões sobre o "corpo In'perfeito": o Cena 11 e as relações entre arte e tecnologia. Motrivivência, Florianópolis, Ano XVI, n. 23, p. 45-60, dez. 2004.

ARAÚJO, B. M. R., et al. Virtualização esportiva e os novos paradigmas para o movimento humano. Motriz, Rio Claro, v. 17 n. 4, p. 600-609, out./dez. 2011.

BÁRTOLO, J. Corpo e sentido: estudos intersemióticos. Covilhã: Livros LabCom, 2007.

CARVALHO, Y. M. MANOEL, E. J. Pós-graduação na educação física brasileira: a atração (fatal) para a biodinâmica. Educação e Pesquisa, São Paulo, v. 37, n. 2, p. 389-406, maio/ago. 2011.

COSTA, A. Q.; BETTI, M. Mídias e jogos: do virtual para uma experiência corporal educativa. Revista Brasileira de Ciências do Esporte, Campinas, v. 27, n. 2, p. 165-178, jan. 2006. 
COSTA, F. S. et al. Doping no esporte: problematização ética. Revista Brasileira de Ciências do Esporte, Campinas, v. 27, n. 1, p. 113-122, set. 2005.

CRAIA, E. C. P. Gilles Deleuze e a questão da técnica. 2003. Tese (Doutorado em Filosofia) - Programa de Pós-Graduação em Filosofia, Instituto de Filosofia e Ciências Humanas da UNICAMP, Campinas, 2003.

CUPANI, A. Filosofia da tecnologia: um convite. Florianópolis: Editora da UFSC, 2011.

DEVIDE, S. P.; VOTRE, S. J. Doping e mulheres nos esportes. Revista Brasileira de Ciências do Esporte, Campinas, v. 27, n. 1, p. 123-138, set. 2005.

FINCO, D. M.; FRAGA, A. B. Rompendo fronteiras na Educação Física através dos videogames com interação corporal. Motriz, Rio Claro, v. 18 n. 3, p. 533-541, jul./set. 2012.

GAMA, D. R. N. Ciberatletas, cibercultura e jogos digitais: considerações epistemológicas. Revista Brasileira de Ciências do Esporte, Campinas, v. 26, n. 2, p. 163-177, jan. 2005.

HEIDEGGER, M. Língua de tradição e língua técnica. Lisboa: Passagens, 1999. JUNIOR, G. C.; SILVA, E. M. A (ciber) cultura corporal no Contexto da rede: Uma leitura sobre os jogos Eletrônicos do século XXI. Revista Brasileira de Ciências do Esporte, Florianópolis, v. 32, n. 2-4, p. 89-104, dez. 2010.

LE BRETON, D. Antropologia do corpo e modernidade. Tradução de Fábio dos Santos Creder Lopes. Petrópolis/RJ: Vozes, 2011.

LESSA, P.; VOTRE, S. J. A tecnofabricação dos corpos sexuados nos testes de feminilidade na olímpiada de 1968. Revista Brasileira de Ciências do
Esporte, Florianópolis, v. 35, n. 2, p. 263-279, abr./jun. 2013.

LÉVY, P. O que é virtual? São Paulo: Editora 34, 1996.

MACHADO, A. A.; ZANETTI, M. C.; MOIOLI, A. O corpo, o desenvolvimento humano e as tecnologias. Motriz, Rio Claro, v. 17 n. 4, p. 728-737, out./dez. 2011.

MANSKE, G. S. Atletas do século XXI: ou das fusões biotecnológicas nos atletas de alto rendimento. Movimento, Porto Alegre, v. 19, n. 01, p. 289-308, jan./mar. de 2013.

MITCHAM, C. ¿Qué es la Filosofía de la Tecnología? Barcelona: Editorial Anthropos, 1989.

NÓBREGA. T. P. Corpo e Epistemologia. In: NÓBREGA.T. P. (ORG.) Epistemologia, saberes e práticas da Educação Física. João Pessoa: Editora Universitária / UFPB, p. 59-74. 2006.

ORTEGA Y GASSET, J. Meditación de la técnica. Madrid: Espasa-Calpe, 1965. PERERA, E.; GLEYSE, J. O doping ao longo do século $X X$ nafrança: representações do puro, do impuro e do segredo. Revista Brasileira de Ciências do Esporte, Campinas, v. 27, n. 1, p. 55-74, set. 2005.

SANTA'ANNA, D. B. Entre o corpo e a técnica: antigas e novas concepções. Motrivivência, Florianopólis, Ano XI, n. 15, p. 1-6, ago. 2000.

SILVA, A. P. S.; FILHO, A. L.; SILVA, A. M. Práticas corporais, experiência e realidade virtual: notas introdutórias. Motrivivência, Florianopólis, Ano XXII, n. 34, p. 170-185, jun. 2010.

TADEU, T. Nós, ciborgues: o corpo elétrico e a dissolução do humano. In: HARAWAY, D.; KUNZRU, H.;______. (Org) Antropologia do 
ciborgue: as vertigens do pós-humano. Belo Horizonte: Autêntica, p. 7-15, 2009.

TAVARES, O. Doping: argumentos em discussão. Movimento, Porto Alegre, v. 8, n. 1, p. 41-55, jan./abril 2002.

VAZ, A. F. Treinar o corpo, dominar a natureza: notas para uma analise do esporte com base no treinamento corporal. Caderno Cedes, Campinas, Ano 9, n. 48, ago. 1999.
. Doping, esporte, performance: notas sobre os "limites" do corpo. Revista Brasileira de Ciências do Esporte, Campinas, v. 27, n. 1, p. 23-36, set. 2005.

ZOBOLI, F.; SILVA, R. I. Cibercultura e educação física: algumas considerações ontológicas. Motrivivência, Florianópolis, Ano XXII, n. 34, jun. 2010.

PHILOSOPHY OF TECHNOLOGY AND PHISICAL EDUCATION: tensions from the body

\begin{abstract}
This article aims to present and situate the Philosophy of Technology as a discipline that consider important questions about the body intervention studies from the technology attached to studies linked to Physical Education. From a search of 05 journals, were visualized 03 themes to analyze: body/movement virtualization; doping; the body attached to technology. As results, finds texts introducing questions related to Philosophy of Technology - epistemological, ontological and axiological problematization. Concludes with observations about the readings made, laying questions to suggest studies from the configuration that was found.
\end{abstract}

Key words: Body; Technology; Philosophy of Technology; Physical Education 
V. $26, \mathrm{n}^{\circ} 43$, dezembro/2014

FILOSOFÍA DE LA TECNOLOGÍA Y EDUCACIÓN FÍSICA: tensiones a partir del cuerpo

\section{RESUMEN}

El artículo tiene como objetivo presentar y situar la Filosofía de la Tecnología como disciplina, que aborda cuestiones importantes a los estudios de las intervenciones del cuerpo en faz a la tecnología conectada a estudios vinculados a la Educación Física. A partir de una búsqueda en 05 periódicos del campo, se visualizó 03 temas para análisis: virtualización del cuerpo/movimiento; doping; cuerpo acoplado a la tecnología. Como resultado, se encontraron textos que presentan cuestiones conectadas a la Filosofía de la Tecnología - problematizaciones de cuño epistemológico, ontológico y axiológico. Concluye con reflexiones sobre el levantamiento realizado, lanzando algunas cuestiones para una perspectiva de estudios a partir de la configuración encontrada.

Palabras clave: Cuerpo; Tecnología; Filosofía de la tecnología; Educación Física

Recebido em: junho/2014

Aprovado em: agosto/2014 